\title{
Designing a Portable Gynecological Examination Table: Improving Access to Antenatal Care in Rural Ghana
}

\author{
Joseph E. Perosky \\ Student \\ Dept of Mechanical Engineering \\ University of Michigan \\ josepero@umich.edu \\ Adam P. Gienapp \\ Student \\ Dept of Mechanical Engineering \\ University of Michigan \\ gienappa@umich.edu
}

\author{
Rebecca N. Rabban \\ Student \\ Dept of Mechanical Engineering \\ University of Michigan \\ rrabban@umich.edu \\ Anthony A. Ofosu \\ Director \\ Sene District Hospital, Ghana \\ anthony.ofosu@ghsmail.org
}

\author{
James G. T. Bradshaw \\ Student \\ Dept of Mechanical Engineering \\ University of Michigan \\ brajames@umich.edu \\ Kathleen H. Sienko \\ Assistant Professor \\ Depts of Mechanical and \\ Biomedical Engr. \\ University of Michigan \\ sienko@umich.edu
}

Abstract - In many of the world's least developed nations, economic and social constraints, inadequate educational opportunities, and poor roads and scarcity of transport make it difficult for pregnant women to receive proper healthcare in rural settings. The specific goal of this design project is to develop an easily assembled portable gynecological exam table for use by Community-based Health Planning and Services (CHPS) workers in the Sene District, Ghana.

Ghanaian and American clinicians were interviewed in order to obtain user requirements for the initial design prototype. The requirements were translated into engineering specifications, and functional decomposition and brainstorming were performed to generate solution concepts in agreement with the engineering specifications. The outcome was a portable gynecological examination table prototype that 1) supported a weight of $142 \mathrm{~kg}$ while only weighing $10 \mathrm{~kg}, 2$ ) had three adjustable back angles of 0,30 , and 60 degrees, 3 ) folded into a $17.8 \times 50.8 \times 50.8 \mathrm{~cm}^{3}$ volume to allow transport by backpack, 4) could be cleaned with bleach, 5) and was fabricated for less than $\$ 100$.

The prototype was fabricated at the University of Michigan and evaluated in Ghana. It was then returned to the University of Michigan for redesign considerations. The redesigned prototype was evaluated to meet the specifications for table weight, support weight, easy cleaning, and durability in a laboratory setting. The redesigned prototype was returned to Ghana, where its usability was reassessed by interviewing and surveying midwives, physicians, and expectant mothers.

Index Terms - Global health design, Ghana, Gynecology, Maternal health

\section{INTRODUCTION}

The most recent report from the World Health Organization (WHO) states that the Maternal Mortality Ratio in Ghana is 350 deaths per 100,000 live births and that the Infant Mortality Rate is 76 deaths per 1,000 live births. ${ }^{1}$ WHO recommends that pregnant women receive at least four antenatal checkups during pregnancy. ${ }^{2}$ However, in rural settings within the least developed 
countries, poor traveling conditions, lack of resources and education, social constraints, and economic limitations make it difficult for pregnant women to receive adequate healthcare. ${ }^{3}$

The two important components of the antenatal checkup are the pelvic examination and measurements of fetal growth and position. Typically, the pelvic exam includes visual external, speculum, and anal exams, palpation (bi-manual) of the cervix, and a Pap smear to check for infection, complications, well-being, and reproductive health. ${ }^{4}$ The expectant mother must be able to open her pelvis at an angle of $35-50^{\circ}$ for best access by the examiner. If a woman living in a rural area cannot or does not want to travel to a hospital, a community healthcare worker or midwife generally uses the pregnant woman's bed or floor of the dwelling to perform such exams. However, the lack of proper equipment and supplies can cause the pregnant woman discomfort and the lack of a clean "platform" for examination can lead to infection. Thus, a portable, safe gynecological examination table is highly desirable.

\section{BENCHMARKING AND PATENT SEARCH}

Product benchmarking and a patent search were performed to gain insights into the desirable features of both stationary and portable gynecological examination tables. Most patents for portable tables involved the design of an attachment to a non-medically designed table. ${ }^{5}$ The most basic examination tables include an adjustable bed and a leg separation mechanism. Leg separation mechanisms include hanging straps, foot holders, and calf support mechanisms offering varied ease of use, range of motion, and level of support.

\section{COMMUNITY-BASED HEALTH PLANNING AND SERVICES}

The rural areas of the Ghanaian health care system are gradually changing from an older clinicalbased system with a central district hospital associated with health centers and static satellite rural clinics to a system of Community-based Health Planning and Services (CHPS). This new system employs community health officers or midwives stationed in district zones who offer close-to-pregnant woman services via home visits. Motorbikes transport CHPS personnel to biweekly outreach clinics and homes. ${ }^{6}$

\section{FIELD SITE LOCATION}

All field site work, including evaluations of the prototypes, was undertaken in the Sene District of the Brong Ahafo Region of Ghana. This district has a population of roughly 105,000 people, and is geographically challenged, with poor roads and widely scattered communities. There are five sub-districts and 275 communities, 37 of which are island communities. Each sub-district has a CHPS compound with two CHPS workers (midwives or community health officers) who provide care for those living in the sub-district. Since travel is difficult for pregnant women and practitioners alike, the majority of daily outreach visits, including prenatal examinations, are performed within the community.

\section{ANTENATAL CARE PROVIDERS IN GHANA}

It is expected that both health care workers and midwives who live and work in CHPS compounds and public health midwives who work in hospitals and rural communities will be the heaviest users of the examination table. Public health midwives can work in hospitals or rural communities and can also provide maternal health care. Additionally, medical doctors provide 
antenatal care, but are secondary in the consideration of a portable examination table since they typically perform exams in a hospital or clinic. ${ }^{6}$

\section{TIMELINE}

\section{MeTHODOLOGY}

The idea for the project was sparked by the Global Intercultural Experience for Undergraduates (GIEU) program at the University of Michigan (UM) in 2008. One author of this paper, Joseph Perosky, was a member of the interdisciplinary group led by Prof. Kathleen Sienko which conducted intensive clinical observations for one month at Komfo Anokye Teaching Hospital in Kumasi, Ghana. Afterwards, three undergraduate mechanical engineering students and Perosky enrolled in the capstone design and manufacturing course (ME 450) offered by the Department of Mechanical Engineering. Their collaboration led to the first prototype which they evaluated in Ghana in 2009. A redesign was performed later the same year and the final design was validated at the Ghanaian field site in 2010.

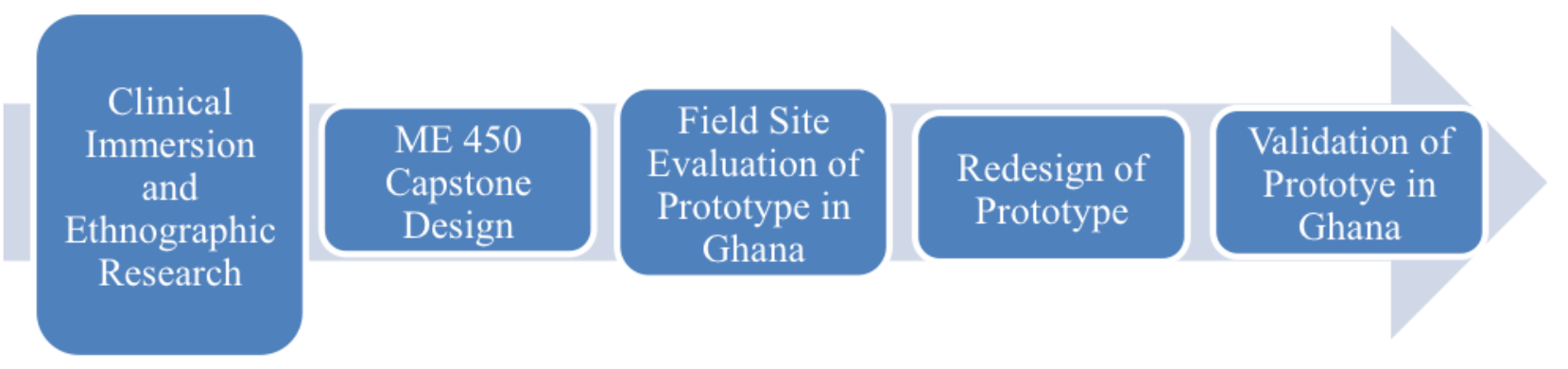

FIGURE 1

FLOWCHART OF TIMELINE FOR DEVELOPMENT AND TESTING OF THE PROTOTYPE

\section{GLOBAL HEALTH DESIGN MINOR}

Perosky was the pilot student for the Multidisciplinary Design Minor: Specialization in Global Health Design (GHD) developed at UM by Prof. Kathleen Sienko and Dr. Aileen Huang-Saad. The GHD Specialization provides interdisciplinary undergraduate engineering students with a rigorous two-semester design course featuring project scoping/clinical immersion in domestic or international clinics, co-creation with the intended target community, technology introduction, and redesign. Students design and manufacture prototypes or sustainable products that address significant global health needs while simultaneously assessing the social venture potential in the communities. ${ }^{7}$

\section{CUSTOMER REQUIREMENTS AND ENGINEERING SPECIFICATIONS}

The co-creative design process included one gynecologist and one midwife from the US and one doctor, six midwives, and six CHPS workers from Ghana. Their input was used to determine both customer requirements and engineering specifications. Table 1 shows the customer requirements and engineering specifications listed in order of importance. 
TABLE 1

USER REQUIREMENTS AND ENGINEERING SPECIFICATIONS

\begin{tabular}{lll}
\hline Rank & User Requirement & Engineering Specification \\
\hline 1 & Light Weight & $\leq 10 \mathrm{~kg}$ \\
2 & Portability & Folded dimensions $\leq 76 \times 76 \times 30.5 \mathrm{~cm}^{3}$ \\
3 & Cost & $\leq \$ 300$ \\
4 & Safety - Support Weight & $\geq 142 \mathrm{~kg}$ \\
5 & Expectant mother Comfort & Bedding thickness $\geq 0.5 \mathrm{~cm}$ \\
& & Two detachable stirrups with leg separation \\
& & range spanning $35-50$ degrees \\
6 & Examiner Comfort & Unfolded dimensions $\geq 157.5 \times 61 \times 50.8 \mathrm{~cm}^{3}$ \\
7 & Lifetime & $\geq 5$ years \\
8 & Non-absorbent & $100 \%$ non-absorbent \\
9 & Non-corrosive & $100 \%$ non-corrosive \\
10 & 3 Adjustable Back Angles & $0,30,60$ degrees \\
11 & Travel Pack Water Resistant & $100 \%$ non-absorbent \\
\hline
\end{tabular}

To determine the required support strength, it was necessary to determine the weight of the $95^{\text {th }}$ percentile of women who would use the table. Nigerian data was used because Ghanaian data was not available. Published anthropometric data for Nigerian women indicated an average weight of $57 \mathrm{~kg}^{8}$ Staff from the Sene District also provided information on the heaviest women (approximately $95 \mathrm{~kg}$ ) in the district. To determine the table's maximum support, a safety factor of 1.5 was applied. The support strength requirement was calculated to be $142 \mathrm{~kg}$.

The clinical partners stressed the importance of sanitation. Since bleach and water or chlorine solutions are the main methods of sanitation throughout Ghana, they requested a non-corrosive, easily cleaned table with an exam surface covered by $100 \%$ non-absorbent material. They also suggested that the backpack carrier had to be $100 \%$ water resistant.

Cost was also a concern. The annual budget of the district evaluating the prototype was $\$ 5,000$ for equipment and instrumentation purchases, but the district was only willing to spend up to $\$ 300$ on a portable examination table.

Healthcare workers and midwives in Ghana often travel for miles on motorized bikes or on foot to reach an expectant mother's home, while the pregnant women themselves often travel on foot for up to six hours to reach a healthcare facility. ${ }^{3}$ Therefore, the examination table was designed to fold down into a backpack. Anthropometric data and the sizes of hiking packs sold in US outdoor stores were studied to find a maximum folded size of $76 \times 76 \times 30.5 \mathrm{~cm}^{3}$. Moreover, a backpack load greater than $30 \%$ of the user's body weight can be detrimental to physical health. ${ }^{9}$ The average Ghanaian woman weighs $55 \mathrm{~kg}$, therefore, $30 \%$ of this weight is $16.5 \mathrm{~kg}^{10}$ Applying a safety factor of 1.5 , the table's total weight was set at less than $10 \mathrm{~kg}$.

\section{CONCEPT GENERATION AND SELECTION}

A functional decomposition was performed prior to brainstorming concept solutions. Multiple brainstorming sessions resulted in the generation of 20 different concept solutions. In order to aid in the selection of the best design solution, Pugh charts were developed for each component, including table legs, back angle adjustment mechanism, and leg separation mechanism. 


\section{DESIGN OF PROTOTYPE}

The selected concept solution consisted of a foot section, middle section, and head section. The middle section, where the pregnant woman sits during the exam, is made from birch plywood covered with plastic (PVC). The table legs, foot section frame, and head section frame are machined from aluminum. The head section frame can be inclined to three positions: $0^{\circ}, 30^{\circ}$, and $60^{\circ}$. The aluminum stirrups attach to the sides of the middle section and are adjustable for length and angle. The head and foot sections are wrapped in a waterproof canvas material (colored blue in Figure 2). A removable, easily stored foot section can be added so that non-gynecological supine exams such as palpations can be performed and to give better access to the pelvic area. A backpack to transport the table was also designed by the team, with the objective of manufacturing the backpacks in Ghana.
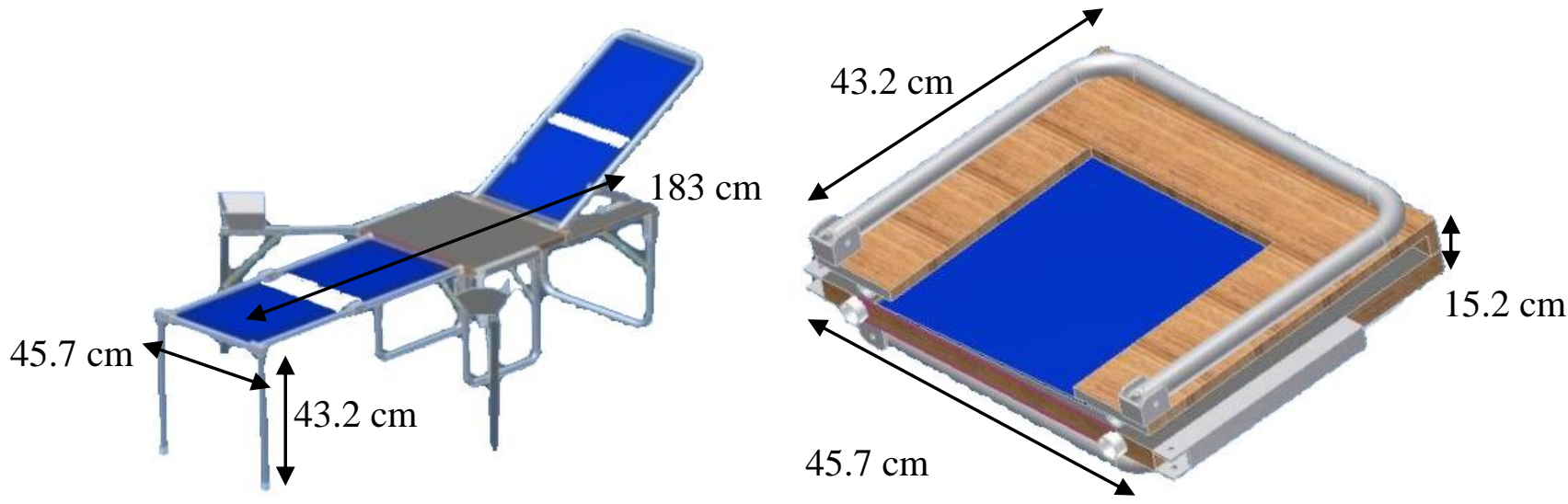

FIGURE 2

UNFOLDED AND FOLDED PROTOTYPE

\section{EVALUATION OF PROTOTYPE AT FIELD Site}

Perosky, who traveled to Ghana in June 2008, returned to Ghana in summer 2009 to evaluate the prototype's use.

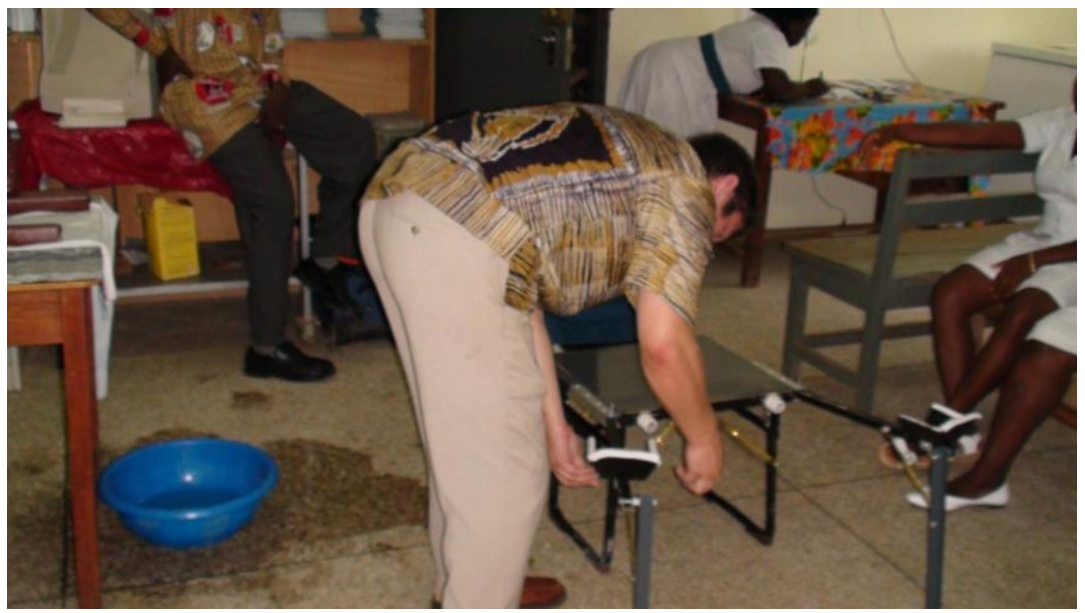

FIGURE 3

PROTOTYPE DEMONSTRATION - SENE DisTRICT, GHANA 


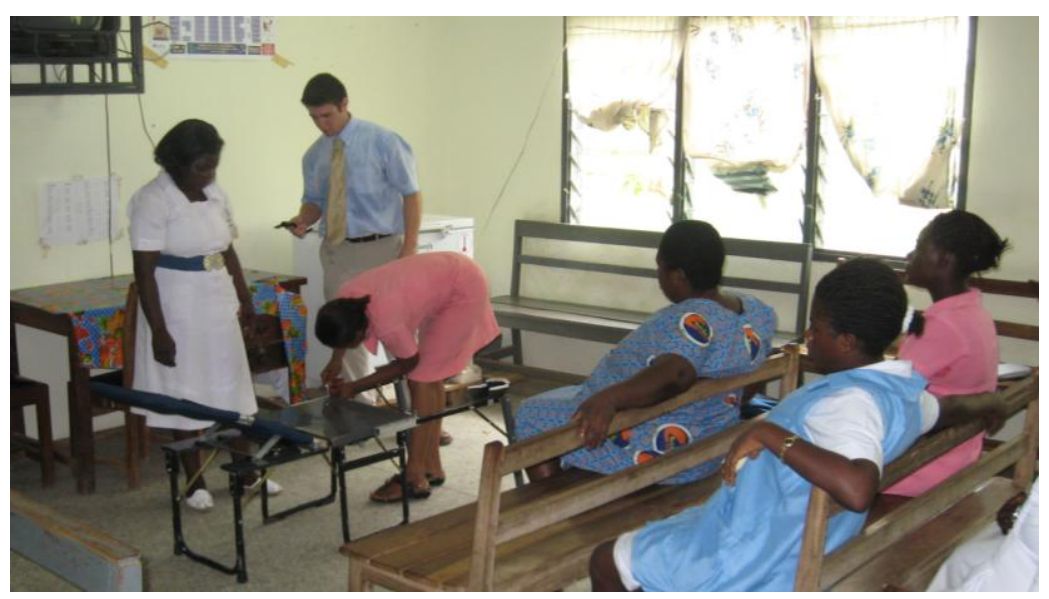

FIGURE 4

MidWIVES DEMONSTRATE TABLE SETUP AND BACK ANGLE ADJUSTMENT (30 ${ }^{\circ}$ - SENE DisTRICT, GHANA

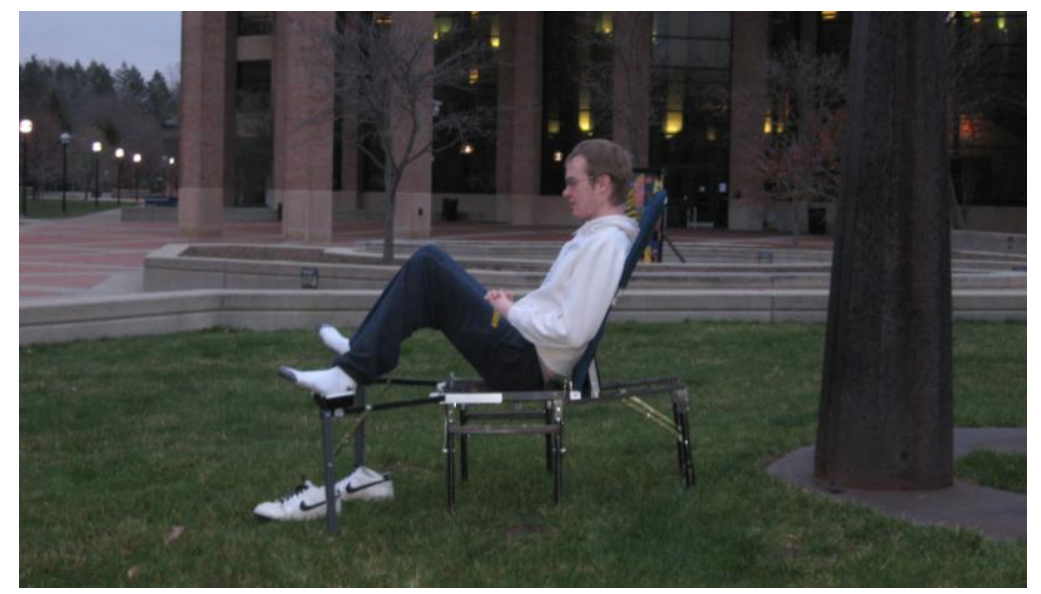

FIGURE 5

TABLE ADJUSTMENT $\left(60^{\circ}\right)$ 


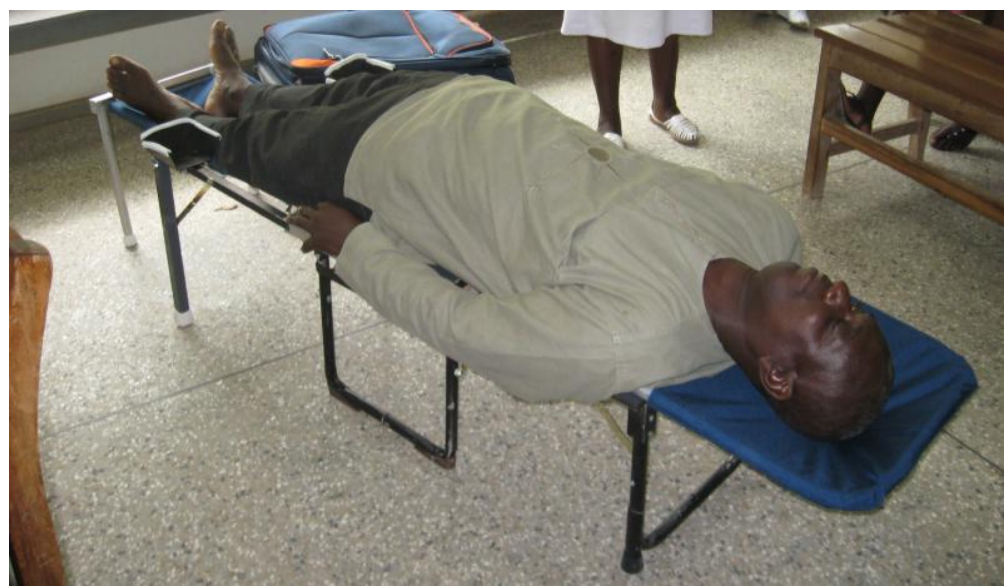

FIGURE 6

COMMUNITY HEALTH NURSE DEMONSTRATES USE OF THE TABLE IN THE SUPINE POSITION - SENE DISTRICT, GHANA

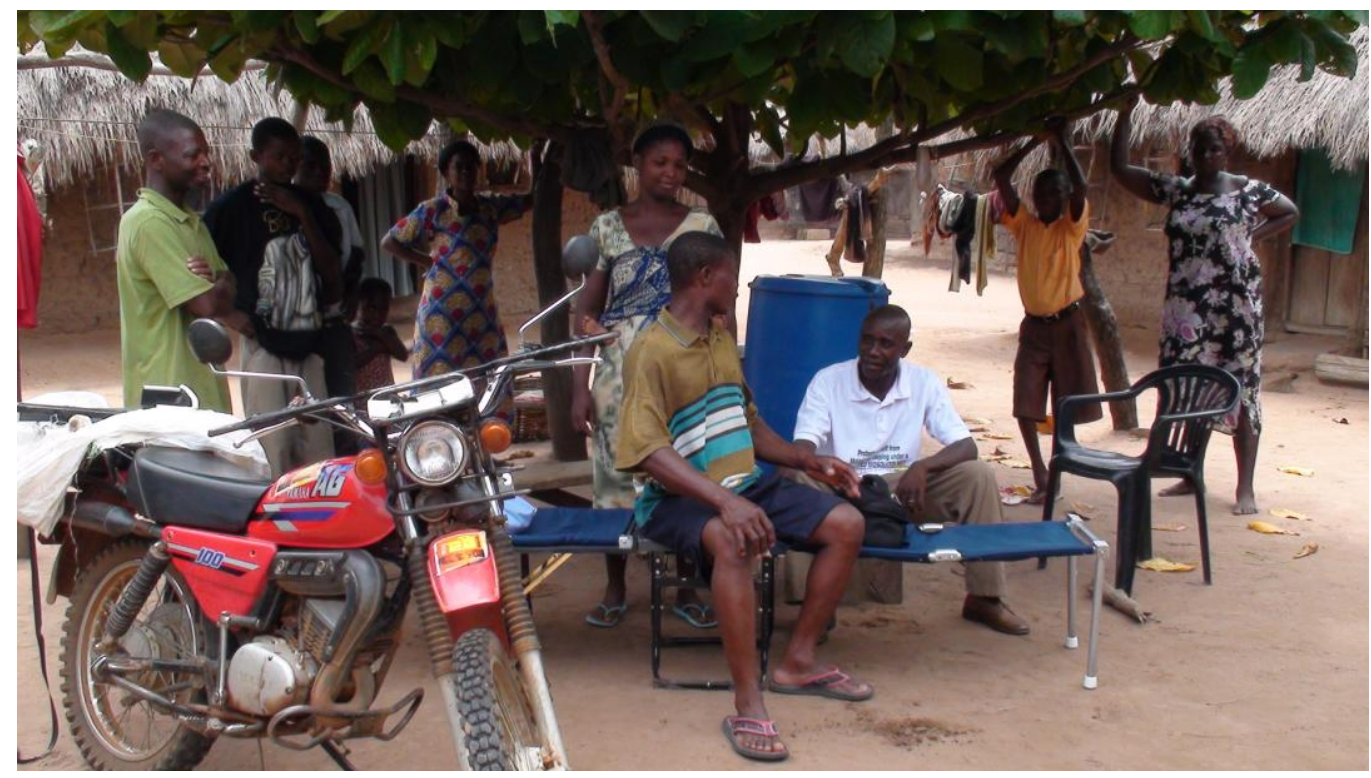

FIGURE 7

COMMUNITY HEALTH OFFICER EVALUATES TABLE USABILITY IN TATOR BATOR VILLAGE - SENE DISTRICT, GHANA. THE MOTORBIKE SHOWN IS TYPICAL OF THOSE USED BY COMMUNITY HEALTH WORKERS.

\section{Functionality}

Functionality was assessed in focus group discussions and individual interviews. Doctors and midwives had the opportunity to assemble and disassemble the table and sit and lie on it. Community members, including mothers, pregnant women, and traditional birth attendants, also had the opportunity to sit and lie on the table and give their input. Most people approved highly of the design. A common critique was that the table was uncomfortable to lie on for extended 
periods due to an offset in the back and middle sections. Some interviewees suggested more padding for comfort.

\section{Cultural Acceptance}

One concern was that the table would not be accepted within the culture. Before entering each village, the author and the community healthcare worker met with the chief. All of the chiefs were very supportive of helping women through the implementation of the table.

\section{Ethics Approval}

Institutional Review Board (IRB) approval was first received from the University of Michigan. The Ghana Health Service Ethics Review Committee then approved the study to be done in Ghana. Both approvals were received before any part of the study was conducted during summer 2010 .

\section{REDESIGNED Prototype}

Following the field site evaluation, the prototype was redesigned. The key changes are discussed. The redesigned prototype is shown in Figures 8 and 9.

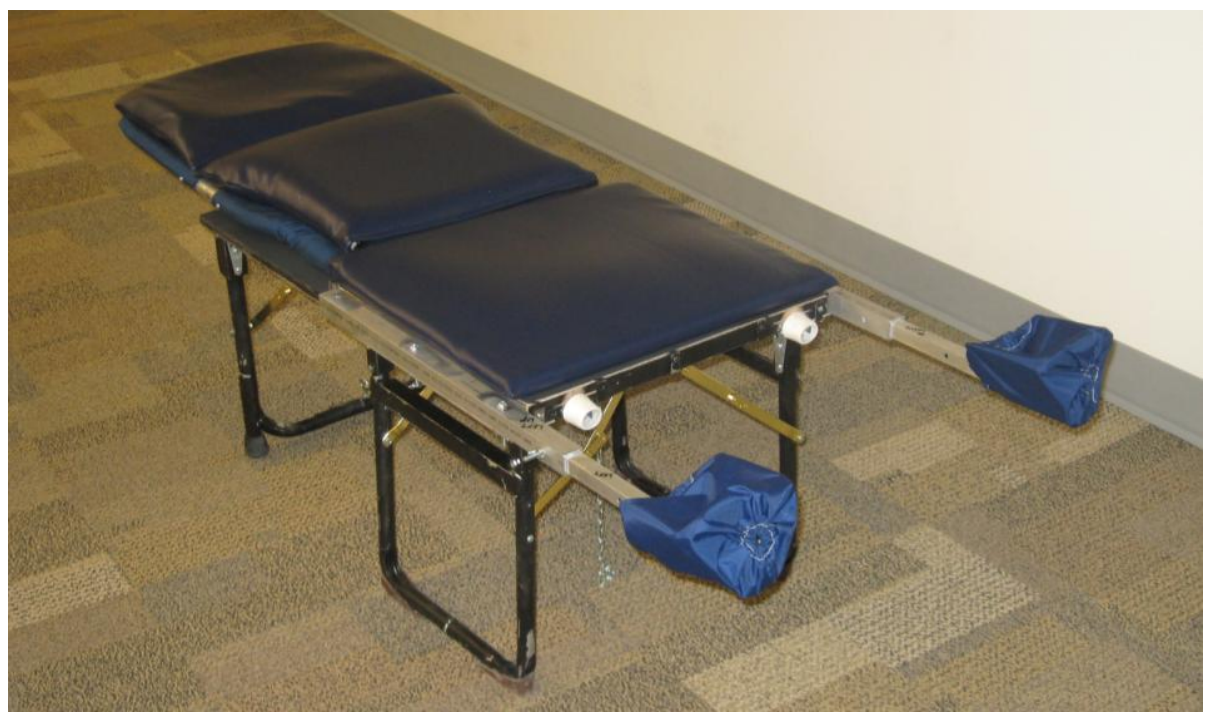

FIGURE 8

REDESIGNED PROTOTYPE 


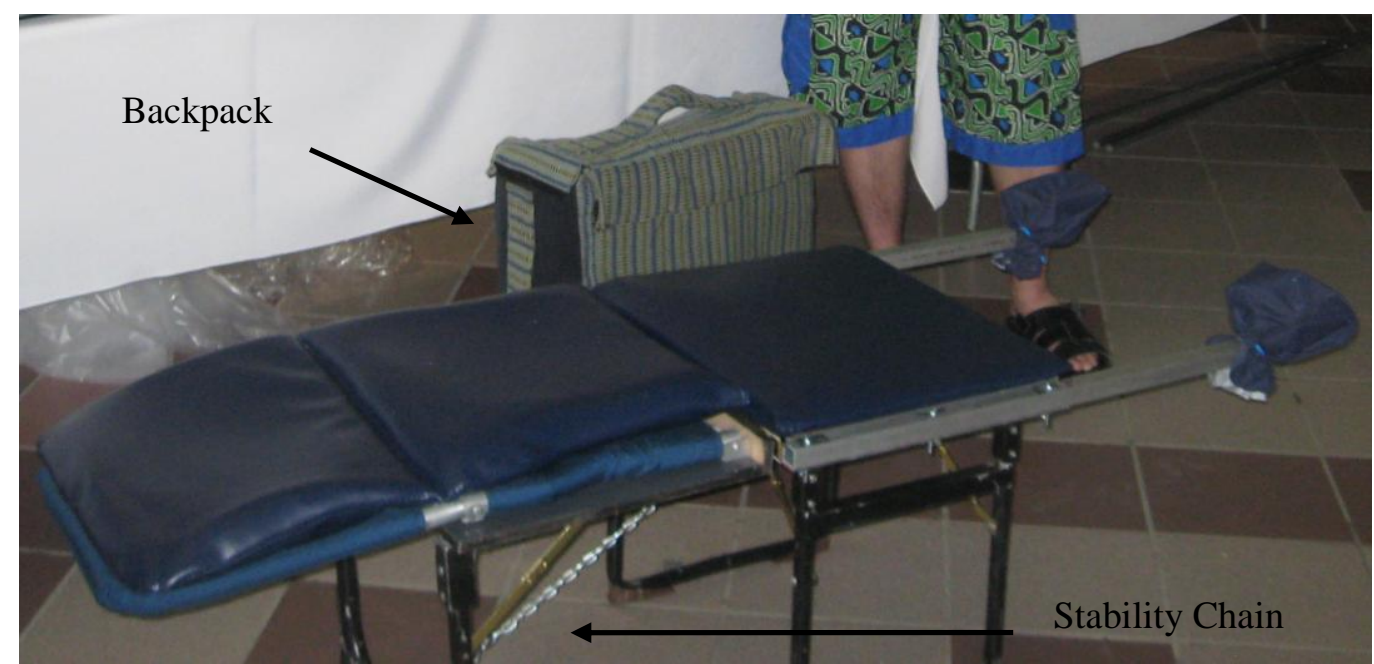

FIGURE 9

REDESIGNED PROTOTYPE WITH STABILITY CHAIN AND BACKPACK

\section{REDESIGN OF THE PROTOTYPE}

The feedback from the field site evaluation identified five elements for redesign:

- Fix offset in the back support section of the table to increase user comfort

- Add more padding

- Change stirrup design to be more robust and improve connection to the table

- Improve stability to keep table from tipping backwards

- Fix back support hinge design to accommodate $142 \mathrm{~kg}$ load

The first two elements were addressed by adding $2.5 \mathrm{~cm}$ of padding to the back support and middle sections. Adding more padding eliminated the existing $2.5 \mathrm{~cm}$ offset between the back of the table and the middle section where the expectant mother sits. The hinge design was improved by adding a support brace made from 6061 T6 aluminum. To increase the load supported by the back brass hinges, bolts replaced the screws that were being used to mount the hinges onto the middle and back sections. Table stability was greatly improved by adding a tensioning chain that secures the table from tipping when in use (when not in use, the chain can be detached and wrapped around the table as a handle). Additionally, a custom designed backpack (see Figure 9) was manufactured in Ghana for \$14. No off-the-shelf backpack that was the same size as the table was available in the US, and manufacturing the bag in the US would have cost at least $\$ 40$. The backpack has three pockets on the outside and one on the inside for carrying items such as a notebook, stethoscope, and gloves. 

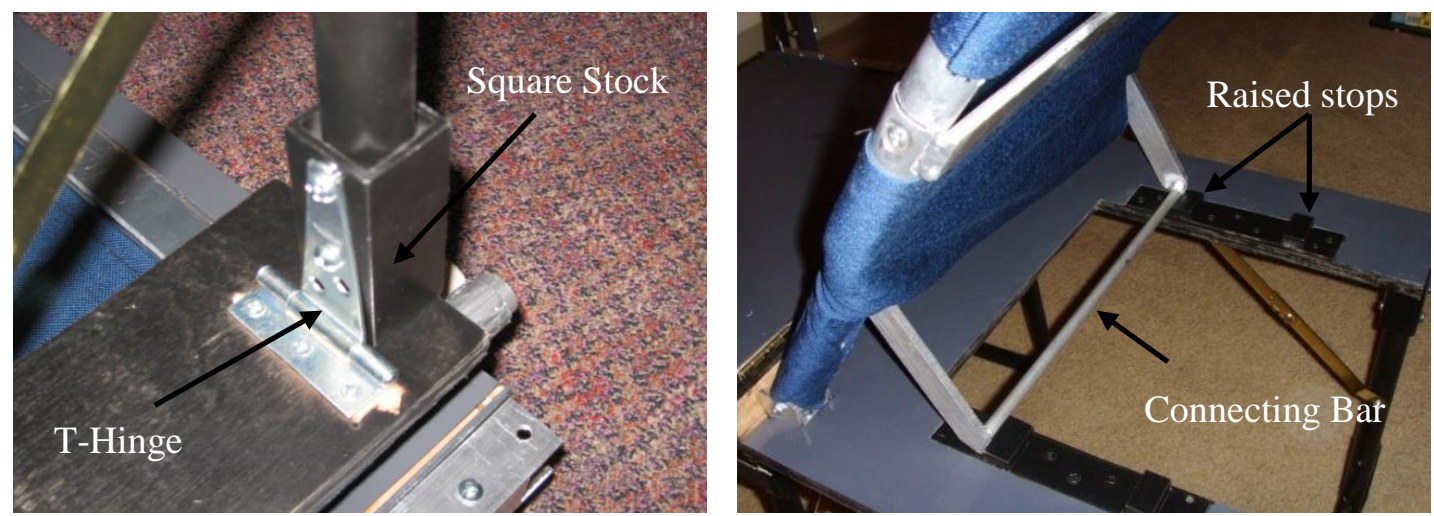

FIGURE 10

HINGES AND ANGLE ADJUSTMENT MECHANISM IN FINAL DESIGN

\section{LEG SEPARATION MECHANISM: CONCEPT GENERATION AND SELECTION}

The most crucial component requiring a redesign was the leg separation mechanism. This problem was presented to a class of capstone design engineering students, and more than 20 different concept solutions were identified. These solutions were then combined with the authors' solutions and presented to the Ghanaian and American clinical partners. One favored design consisted of elastic and fabric bands that would connect to the expectant mother's upper torso and around the upper thigh. Theoretically, the solution would open the pelvis area for easier clinical access. It would also be lightweight and cost effective. The concept ultimately chosen uses aluminum housings and cups to adjust the length of the stirrup in a robust manner that easily supports the force applied by the expectant mother's legs. The stirrup design is manufactured from 6063 aluminum with an outer diameter of $2.54 \mathrm{~cm}$ and an inner diameter of $2.22 \mathrm{~cm}$.

\section{Evaluation ANd Results Of THE Redesigned Prototype}

Parameter analyses and experimental tests were performed to evaluate the design and material selection as summarized in Table 2 . A $142 \mathrm{~kg}$ weight, i.e. the maximum calculated value that the table needed to support based on the safety factor, was applied to test the redesigned prototype. 
TABLE 2

ENGINEERING ANALYSIS OF REDESIGNED PROTOTYPE

\begin{tabular}{llll}
\hline Analysis & $\begin{array}{l}\text { Calculated Load } \\
\text { Capability }\end{array}$ & $\begin{array}{l}\text { Maximum } \\
\text { Tested Load }\end{array}$ & $\begin{array}{l}\text { Specification } \\
\text { Pass/Fail }\end{array}$ \\
\hline Buckling in Legs & $365.3 \mathrm{~kg}$ & $142 \mathrm{~kg}$ & Pass \\
Stress in Middle Section & $320.7 \mathrm{~kg}$ & $142 \mathrm{~kg}$ & Pass \\
Weight Supported by Stirrup Legs & $495.3 \mathrm{~kg}$ & $142 \mathrm{~kg}$ & Pass \\
Compressive Stress in Adjustment Rod & $234.4 \mathrm{MPa}$ & $17.24 \mathrm{MPa}$ & Pass \\
Buckling in Adjustment Rod & $1888 \mathrm{~kg}$ & $142 \mathrm{~kg}$ & Pass \\
Max Deflection of Table Base & $0.254 \mathrm{~cm}$ & N/A & Pass \\
\hline
\end{tabular}

\section{EVALUATION TESTING OF REDESIGN}

Before the prototype redesign was reevaluated at the field site, it underwent testing to determine how well it met the engineering specifications. All specifications listed in Table 1 were met. To test the support weight target value of $142 \mathrm{~kg}$, the table was loaded with $145 \mathrm{~kg}$ on a flat, indoor surface as well as an uneven, outdoor surface. The table easily supported this weight in both cases. The table was found to weigh approximately $10 \mathrm{~kg}$. The back angle adjustments and stirrup angles were measured using an electronic protractor. The back angle adjustments of $0^{\circ}$, $30^{\circ}, 60^{\circ} \pm 1^{\circ}$ were confirmed. The stirrups were specified to range from $35-50^{\circ}$. A thumbscrew was used to meet this specification, allowing for a $0-90^{\circ}$ range.

A corrosion test was completed on the wood, aluminum, brass, and PVC. The materials were soaked for 72 hours in a bleach/water solution identical to the solution used by Ghanaian health care workers for disinfection and then left to dry for 24 hours. No corrosion was observed. The travel backpack made from commercial water-resistant $45.7 \times 45.7 \times 25.4 \mathrm{~cm}^{3}$ of $210 \mathrm{D}$ antimicrobial nylon / 600D polyester was tested for permeability. The unfolded dimensions of the table were found to be $182.9 \times 45.7 \times 43.2 \mathrm{~cm}^{3}$, and the folded dimensions were found to be $45.7 \times 43.2 \times 15.2 \mathrm{~cm}^{3}$. Both folded and unfolded dimensions met the specifications.

\section{Interviews}

Ten interviews were conducted in the Sene District to 1) evaluate the impact of the gynecological table on the desire of women in the village to receive gynecological checkups and 2) assess the acceptance and feasibility of the examination table in comparison to current methods for gynecological care. Five of the subjects were health care professionals (three midwives and two community health care workers) who would be using the table to perform examinations. The other five subjects were mothers in the district who had received antenatal care during their pregnancies.

The health care professionals and mothers were given a demonstration of how the table would be used and could ask any relevant questions. Next, they filled out a Likert-based survey 
(19 questions for the health care professionals, 9 questions for the mothers). The survey responses are summarized in Tables 3 and 4.

TABLE 3

PERCEPTION OF THE EXAMINATION TABLE BY HEALTHCARE PROFESSIONALS

\begin{tabular}{lll}
\hline Value Dimension & Mean* & Std. Deviation \\
\hline Use of this table would increase access to gynecological care in my district. & 4.60 & 0.50 \\
The table would be easy to transport. & 4.64 & 0.50 \\
The table would be easy to use and assemble in rural communities. & 4.20 & 0.77 \\
I prefer this table over current options. & 4.30 & 0.80 \\
I am willing to pay/ask for this table. & 4.40 & 0.50 \\
\hline
\end{tabular}

*Note: Scale Range 1=strongly disagree, $2=$ disagree, $3=$ neutral, 4=agree, 5=strongly agree.

TABLE 4

PERCEPTION OF THE EXAMINATION TABLE By MOTHERS IN THE SENE District

\begin{tabular}{lll}
\hline Value Dimension & Mean* & Std. Deviation \\
\hline $\begin{array}{lll}\text { Availability of table would increase my willingness to receive examination. } \\
\text { I regularly visited a health care provider during my pregnancy. }\end{array}$ & $\begin{array}{l}1.05 \\
\text { The table would increase access to antenatal care. }\end{array}$ & 0.40 \\
$\begin{array}{l}\text { I would prefer to have a gynecological examination on this table compared } \\
\text { to what is currently available. }\end{array}$ & 4.60 & 0.5 \\
\end{tabular}

*Note: Scale Range 1=strongly disagree, 2=disagree, 3=neutral, 4=agree, 5=strongly agree.

\section{DISCUSSION}

The interviews and conversations with healthcare workers, mothers, and members of the Ministry of Health in Ghana proved to be very supportive of the implementation of the table in rural districts. Limitations of these results are 1) interviews were performed only in one district, and 2) small $(\mathrm{n}=10)$ sample size. The sample size was planned to be larger, but the unexpectedly lengthy ethics review process allowed time for only 10 interviews.

Entering, Immersion in, and Exiting the Community

Responsible behavior includes ensuring that all involved parties are aware of and agree with the planned activities (i.e., awareness of and following cultural customs and norms, meeting with appropriate officials, and being transparent about the information and materials to be collected and distributed before, during and after the visit). A unique element of the methodology for this 
project was the fact that Perosky took three trips to Sene District, for a total of seven months. He lived with three different host families as well as living in various hospital compounds. The trips gave him the opportunity to interact with and get to know many of the potential end users. Perosky has since maintained close contact with his host families and many of the clinicians.

\section{Funding Mechanisms}

While it is crucial to a project's success to develop sustainable relationships and to enter and exit a community in a responsible manner, it is also important to build upon such relationships over time. A project should not be viewed as simply a "one and done" operation. However, numerous trips require adequate funding. This student project relied on four funding mechanisms:

1) Traditional NIH, NSF, or other government funding sources, while ideal, are usually not realistic for pilot study work, especially for student projects.

2) Private foundations providing support for global health initiatives include the Bill and Melinda Gates Foundation, the Clinton Global Initiative University, and the Davis Projects for Peace.

3) Campus programs, grants, and fellowships include the College of Engineering, Center for Global Health, the William Davidson Institute, the International Program for Engineering, the Ginsberg Center, and the Global Intercultural Experience for Undergraduates.

4) Donations from friends and family.

\section{Additional Applications}

Although the table was designed to be used for gynecologic examinations, it can be used for other procedures and examinations, such as routine physical examination on a male or female. For these exams, the provider would detach the stirrups. It can support an expectant mother weighing up to $142 \mathrm{~kg}$. Additions could be made to the current design to make it suitable to stabilize someone with a fracture for transportation to a clinic, to restrain an expectant mother having a seizure, etc.

\section{FUTURE WORK}

The next steps are: 1) perform a detailed market analysis and large-scale implementation plan, and 2) evaluate the clinical usage of the table. The market analysis will be used to determine the best locations for table manufacturing and distribution as well as the scalability of the project. Further implementation of the table is being planned in Nicaragua by M-HEAL, a student-based co-curricular organization at the University of Michigan. A cross-cultural evaluation and analysis, which are rare in the development of medical devices for global health, are additional topics for study.

\section{ACKNOWLEDGMENTS}

Support for this work was provided by the University of Michigan College of Engineering, Center for Global Health, Multidisciplinary Design Minor, and Global Intercultural Experience for Undergraduates; National Collegiate Inventors and Innovators Alliance (Course and Program Grant); and the National Science Foundation's CAREER program (RAPD-0846471, funded 
under the American Recovery and Reinvestment Act of 2009). The authors thank Dr. Tim Johnson, Dr. Jodi Lori, Domitilla Debpuur, Cynthia Abendshien, John Abendshien, Amir Sabet, Dr. Steve Skerlos, Dr. Brent Gillespie, Dr. Gregory Hulbert, and Daniel Johnson for their input. They also acknowledge Bob Coury and Jerry Stout for their help in manufacturing the prototypes.

\section{REFERENCES}

${ }^{1}$ World Health Organization, “Trends in Maternal Mortality: 1990 - 2008.” 2010.

${ }^{2}$ WHO antenatal care randomized trial: manual for the implementation of the new model. WHO/RHR/01.30. Geneva, World Health Organization, 2001.

3 Thaddeus, Serene and Deborah Maine, "Too Far to Walk: Maternal Mortality in Context." Social Science Med. 38, no.8 (1994), 1091-1110.

${ }^{4}$ Rathe, Richard, "Examination of the Female Pelvis."Aug. 1996. University of Florida. 10 Feb. (2009). http://medinfo.ufl.edu/year1/bcs/clist/pelvic.html.

5 Torrey, Robert, “Genito-Urinary Examination Device.” US Patent \# 3817512. 18 June (1974).

${ }^{6}$ Nyonator, Frank and Koku Awoonor, "The Ghana Community-based Health Planning and Services Initiative for Scaling Up Service Delivery Innovation.” Health Policy and Planning 20, no. 1 (2005), 25-34.

7 Global Health Design (GHD) Specialization. Accessed November 11, 2011. http://sitemaker.umich.edu/specialization/home.

8 Danborno, B. and Juliet E. Oyibo, "Anthropometric and Menstrual Characteristics of Girls from Nigeria and Niger Republic." The Internet Journal of Biological Anthropology 2, no. 1 (2008).

${ }^{9}$ Hardin, D. and Kelly, "You and Your Gear: Physical Fitness.” Backpacker, (1975).

${ }^{10}$ Cappuccio, Francesco, "Prevalence, Detection, Management, and Control of Hypertension in Ashanti, West Africa." Journal of the American Heart Association, no. 43 (2004), 1017-1022. 